\title{
Saturday night broad QRS complex tachycardia in a young male
}

\author{
J. E. C. van de Swaluw • R. van Mechelen
}

Published online: 21 November 2013

(C) The Author(s) 2013. This article is published with open access at Springerlink.com

On a Saturday night, a 24-year-old male with palpitations was admitted to the Emergency Department. The arrhythmia started $8 \mathrm{~h}$ earlier while he was riding his bicycle. He had never experienced this sensation before. He admitted prior usage of cocaine, LSD and XTC. He denied the use of any drugs on the night of presentation.
Physical examinations revealed no abnormalities except a very fast heart rate. The arrhythmia did not respond to carotid sinus massage. Laboratory investigation demonstrated no abnormalities. The ECG on admission is shown (Fig. 1). Spontaneously the rhythm changes (Fig. 2). What is your diagnosis? 


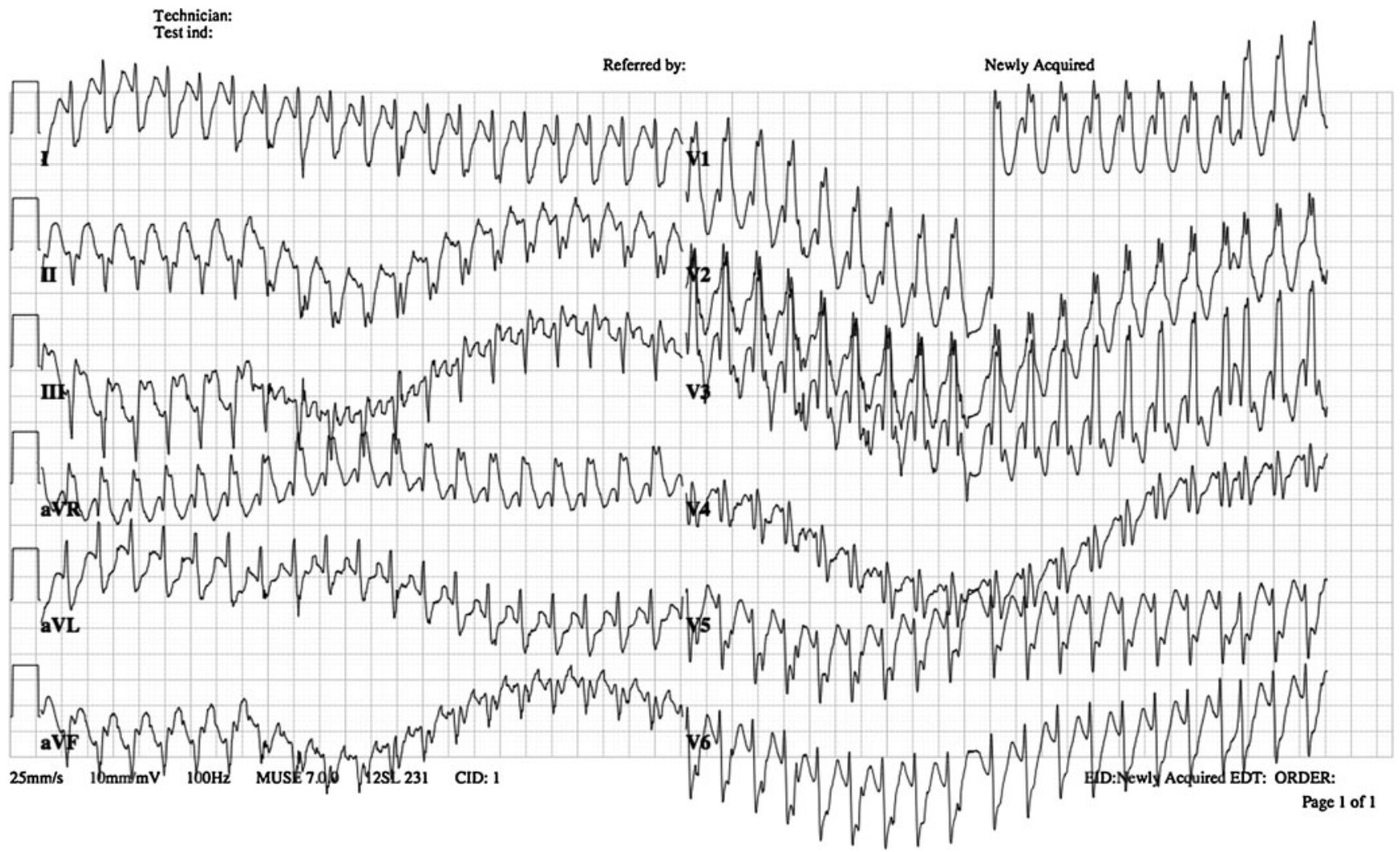

Fig. 1 ECG on admission

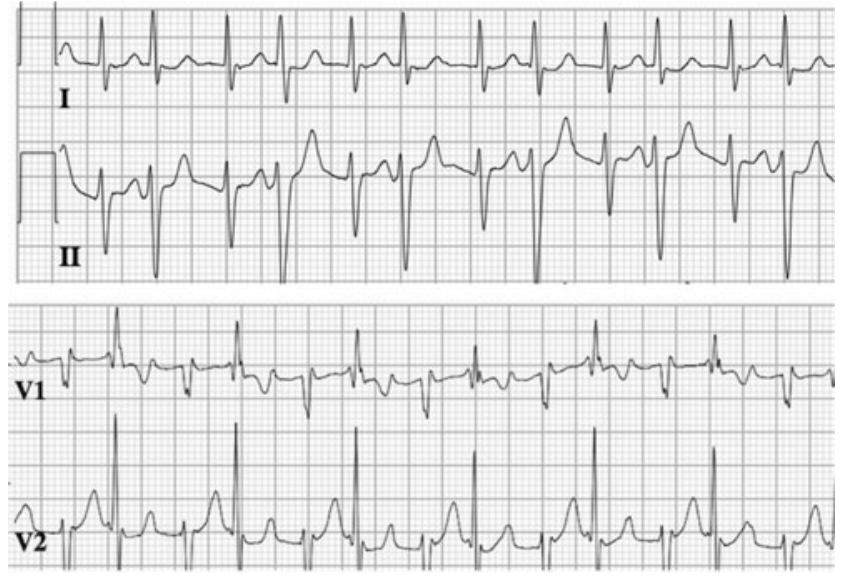

Fig. 2 ECG a few minutes after admission

\section{Answer}

You will find the answer elsewhere in this issue.

Open Access This article is distributed under the terms of the Creative Commons Attribution License which permits any use, distribution, and reproduction in any medium, provided the original author(s) and the source are credited. 